\title{
Reductive power of the archaea right-handed coiled coil nanotube (RHCC- NT) and incorporation of mercury clusters inside protein cages
}

\author{
Matthew McDougall ${ }^{\mathrm{a}, \mathrm{b}}$, Kevin McEleney ${ }^{\mathrm{c}}$, Olga Francisco ${ }^{\mathrm{a}, \mathrm{b}}$, Benchmen Trieu ${ }^{\mathrm{a}}$, \\ Efehi Kelly Ogbomo ${ }^{\mathrm{a}}$, Gregg Tomy ${ }^{\mathrm{a}, \mathrm{b}}$, Jörg Stetefeld ${ }^{\mathrm{a}, \mathrm{b}, \mathrm{d}, \mathrm{e}, *}$ \\ ${ }^{a}$ Department of Chemistry, University of Manitoba, 144 Dysart Rd, Winnipeg, Manitoba, Canada \\ ${ }^{\mathrm{b}}$ Center for Oil and Gas Research and Development (COGRAD), Canada \\ ${ }^{\mathrm{c}}$ Manitoba Institute for Materials Science (MIM), University of Manitoba, Canada \\ ${ }^{\mathrm{d}}$ Department of Biochemistry and Medical Genetics, University of Manitoba, Canada \\ ${ }^{\mathrm{e}}$ Department of Human Anatomy and Cell Science, University of Manitoba, Canada
}

\section{A R T I C L E I N F O}

\section{Keywords:}

Archaea

S-layer

Right-handed coiled coil

Reduction of metals

Cluster uptake via protein cage

Synchrotron-XRD

XPS

\begin{abstract}
A B S T R A C T
Coiled coils are well described as powerful oligomerization motifs and exhibit a large diversity of functions, including gene regulation, cell division, membrane fusion and drug extrusion. The archaea S-layer originated right-handed coiled coil -RHCC-NT- is characterized by extreme stability and is free of cysteine and histidine moieties. In the current study, we have followed a multidisciplinary approach to investigate the capacity of RHCC-NT to bind a variety of ionic complex metal ions. At the outside of the RHCC-NT, one mercury ion forms an electrostatic interaction with the S-methyl moiety of the single methionine residue present in each coil. We demonstrate that RHCC-NT is reducing and incorporating metallic mercury in the large-sized interior cavities which are lined up along the tetrameric channel.
\end{abstract}

\section{Introduction}

The $\alpha$-helical coiled coil is the most frequently encountered subunit oligomerization motif found in proteins (Burkhard et al., 2001; Lupas and Bassler, 2017; Lupas and Gruber, 2005). Typically, coiled coils consist of two to five right-handed amphipathic $\alpha$-helices that are intertwined to a left-handed superhelix. Based on the presence of undecad repeats, a right-handed coiled-coil structure has been proposed for the C-terminus of the surface layer glycoprotein tetrabrachion from the hyperthermophilic archaebacterium Staphylothermus marinus (S. marinus) (Peters et al., 1996; Peters et al., 1995). The 1.7 MDa tetrabrachion protein complex consists of four identical subunits that form an $\alpha$-helical coiled-coil stalk of $70 \mathrm{~nm}$ length, which is anchored to the cell membrane at its C-terminal end and branches into four arms of $24 \mathrm{~nm}$ length at its $\mathrm{N}$-terminus. The arms form a canopy-like meshwork by end-to-end contacts, enclosing a "quasi-periplasmic space" (Mayr et al., 1996). S. marinus, isolated from the periphery of black smoker vents, is a strict anaerobic sulfur reducing archaeon that employs these extremely stable proteinaceous S-layer as protective shield arranged in a 2D-network coating the archaeon (Hao and Ma, 2003; Fiala et al., 1986).

A $24 \mathrm{kDa}$ segment of this tetrabrachion forms the tetrameric right handed coiled-coil nanotube (RHCC-NT) (Stetefeld et al., 2000). RHCCNT is a cysteine -and histidine free protein segment that has extreme stability with respect to temperature, $\mathrm{pH}$ and salinity (McDougall et al., 2017). The tetramer structure is stabilized by a complex pattern of complementary hydrophobic interactions between neighboring helices Fig. 1). The side chain packing of the core residues at the undecad $\mathbf{a}$ and $\mathbf{h}$ positions point into the center of the tetramer and are packed in a perpendicular and parallel manner, respectively. As a consequence, four large cavities of the tetramer are connected to a continuous central channel, which is exclusively lined with aliphatic side chains. The cavities lay in between the middle of the $\mathbf{d}$ and $\mathbf{e}$ layers and have sizes in between $150 \AA^{3}$ and $360 \AA^{3}$. In the native structure, the cavities are occupied with water molecules. A large buried surface of $\sim 9.500 \AA^{2}$ provides further support that the hydrophobic interactions are likely the main cause for the extraordinary thermal stability of the tetrabrachion stalk domain which resists denaturation at $130^{\circ} \mathrm{C}$ in the presence of strong denaturants such as $1 \%(\mathrm{w} / \mathrm{v})$ dodecyl sulfate or $6 \mathrm{M}$ guanidine (Peters et al., 1995; Mayr et al., 1996).

A characteristic feature of the RHCC-NT sequence is the high content $(\sim 27 \%)$ of charged residues. On the basis of distance criteria, all charged residues with the exception of Glu 6 and Asp 43 appear to form intra- and/or interhelical salt bridges. The three intra- and four

\footnotetext{
* Corresponding author at: Department of Chemistry, University of Manitoba, 144 Dysart Rd, Winnipeg, Manitoba, Canada.

E-mail address: Jorg.stetefeld@umanitoba.ca (J. Stetefeld).
} 


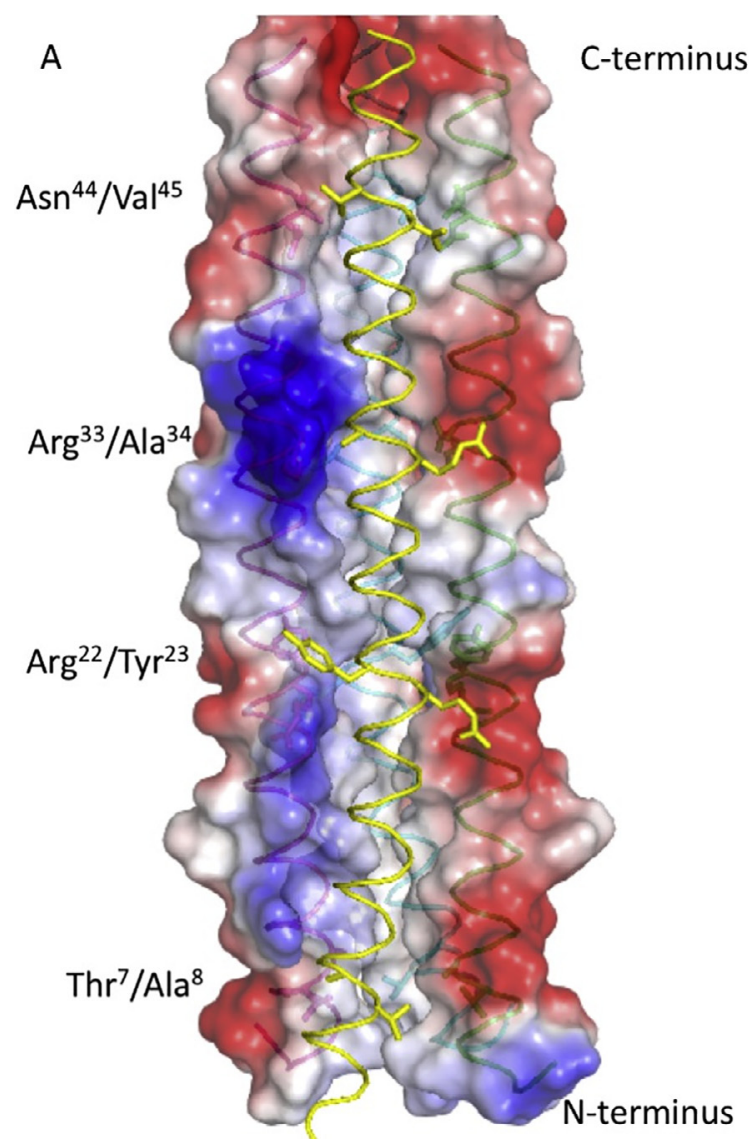

B

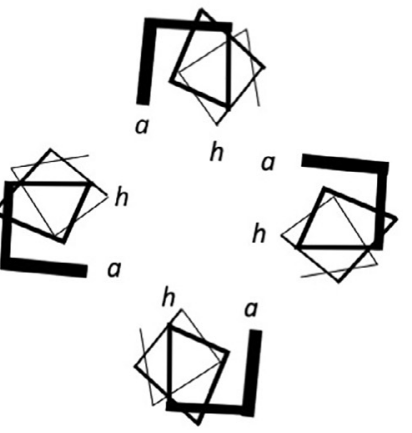

C

\begin{tabular}{lllllllllllll} 
& $a$ & $b$ & $c$ & $d$ & $e$ & $f$ & $g$ & $h$ & $i$ & $j$ & $k$ \\
\hline $1-3$ & & & & & & & & & G & S & I \\
4-11 & I & N & E & T & A & D & D & I & & & \\
$12-18$ & & & & & V & Y & R & L & T & V & I \\
19-29 & I & D & D & R & Y & E & S & L & K & N & L \\
$30-40$ & I & T & L & R & A & D & R & L & E & M & I \\
$41-51$ & I & N & D & N & V & S & T & I & L & A & S \\
\hline
\end{tabular}

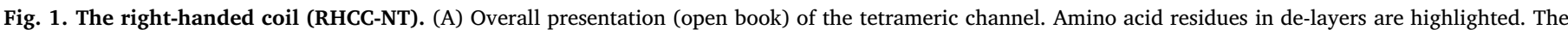

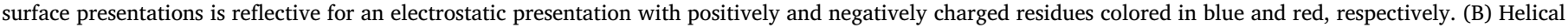

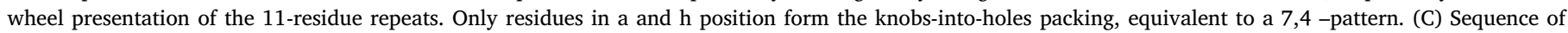
RHCC-NT aligned to the undecad repeat pattern.

interhelical salt bridges are occupied in all chains of the tetramer crystal structure. This frequency of favorable electrostatic interactions has not been observed previously in any other coiled-coil structure solved to atomic resolution and may be explained in terms of the hyperthermophilic nature of the protein.

The four large cavities of RHCC-NT were identified originally as highly efficient binders for heavy atom derivatives to determine the first crystal structure of a naturally occurring right-handed coiled coil (Stetefeld et al., 2000; Ozbek et al., 2005). In subsequent studies, the uptake of anti-cancer drugs such as cis-Pt/ $\mathrm{PTCl}_{4}$ was exploited to develop targeted Carrier-Pathfinder systems (Eriksson et al., 2009; Thanasupawat et al., 2015; McFarlane et al., 2009). In addition, QM/ MM studies revealed unique gas phase properties for the hydrophobic cavities upon coordination of uranyl complexes (Odoh et al., 2011). Most recently, the uptake of elemental sulfur S8 crowns has been shown by mimicking black smoker conditions. In conjunction with atomistic MD simulations it is clear, that filling the large-sized cavities has a highly favorable transfer free energy (Yin et al., 2007).

The incorporation of metals into de novo proteins has been reported extensively in the literature (Peacock, 2016). Most of the reported studies concentrate on artificially designed coiled coils or helical bundles with a focus on the insertion of cysteine and histidine side chains to allow for mono -and multinuclear chelation of different metal compounds (Matzapetakis et al., 2002; Peacock, 2013; Zastrow et al., 2011). The design of aspartate and asparagine moieties in trimeric coiled coil motif has been proven to be efficient for sequestration of ionic metals in the hydrophobic core of the peptide elements (Berwick et al., 2014; Hartmann et al., 2009). On the other hand, the sulfurcontaining side chain of methionine is unbranched and provides considerable conformational flexibility combined with unusually large polarizability of the sulfur atom itself (Gellman, 1991). There are different studies showing, for example, a water-shielding effect of thioethers of methionine residues (Orriss et al., 2010) or the coordination of Platinum (IV) via Met39 of RHCC-NT (Thanasupawat et al., 2015). The thioether moiety provides a common qualitative feature for binding metal ions by providing a center of high hydrophobicity contrast (Yamashita et al., 1990).

In this study, the capability of the naturally occurring RHCC-NT to interact with bivalent and trivalent cations, such as $\mathrm{Hg}^{2+}, \mathrm{Cu}^{2+}$ and $\mathrm{Au}^{3+}$ was investigated. The research goal was to determine what if any type of bivalent cation is capable of binding to RHCC-NT, in a thiol -and imidazole-free environment. The authors have performed an integrated approach combining anomalous dispersion experiments at synchrotron sources with determinations of the reductive power via X-ray photoelectron spectroscopy. The data presented indicate that RHCC-NT has not only a strict reductive power for bivalent cations, it also incorporates reduced mercury clusters inside the hydrophobic cavities.

\section{Results}

To study the uptake of heavy metal complexes by RHCC-NT we followed an integrated approach combining X-ray photoelectron spectroscopy (XPS) and synchrotron-based X-ray crystallography (XRD).

\subsection{XPS to study reduction behavior}

X-ray photoelectron spectroscopy was undertaken to determine the oxidation state of the metal atoms incorporated into the RHCC-NT 
Table 1

$\mathrm{X}$-ray photoelectron spectroscopy of RHCC-NT-Au/ incorporation into RHCC-NT.

\begin{tabular}{ll}
\hline Metal & BE (eV) \\
\hline $\mathrm{Au}$ & $84.6 \pm 0.4$ \\
$\mathrm{Cu}$ & $932.7 \pm 0.09$ \\
$\mathrm{Hg} \mathrm{K} \mathrm{I}_{4}$ & $100.8 \pm 0.2$ \\
$\mathrm{Hg}\left(\mathrm{NO}_{3}\right)_{2}$ & $101.1 \pm 0.2$ \\
\hline
\end{tabular}

protein. Table 1 summarizes the binding energies of the $\mathrm{Au}, \mathrm{Cu}$, and $\mathrm{Hg}$ atoms after incorporation into the RHCC-NT, in comparison to unbound metal complexes.

Starting with $\mathrm{CuCl}_{2}$, measured in our spectrometer to have a binding energy of $935.1 \mathrm{eV}$, a reduction of $\mathrm{Cu}$ by incorporation into RHCC-NT is clear by the shift of peak position $(932.7 \mathrm{eV})$ and lack of shake-up peaks in the spectra Fig. 2 and Supplement Fig. 1. However, due to the low abundance of $\mathrm{Cu}$ in the RHCC-NT complex there is an absence of clear $\mathrm{Cu}$ Auger peaks making differentiation between $\mathrm{Cu}(0)$ and $\mathrm{Cu}(\mathrm{I})$ difficult. Given the size of the cavity and lack of space for a counter ion, the data suggest $\mathrm{Cu}(0)$ as a likely assignment.

Gold atoms have also undergone a reduction upon incorporation into RHCC, $\mathrm{KAuCl}_{4}$ has a binding energy of $87.34 \mathrm{eV}$ (Dalili et al., 2010), while the $\mathrm{Au}$ atoms incorporated into the protein have a binding energy of $84.6 \mathrm{eV}$ Fig. 2. This value is slightly larger than metallic $\mathrm{Au}$ $83.95 \mathrm{eV}$ (Seah et al., 1998), however, as the size of a metal sample decreases from bulk metal to small cluster to single atom, the binding energy is expected to shift to higher energies and therefore our binding
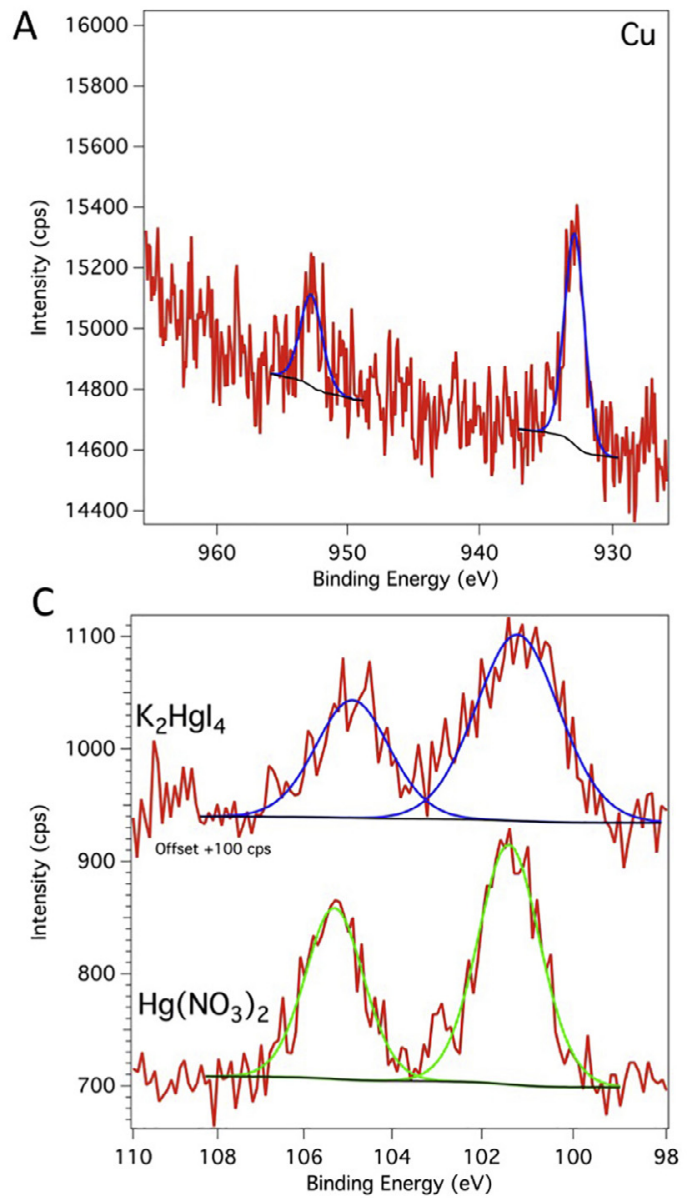
$\mathrm{Cu} / \mathrm{Hg}$. Binding energy (BE) of metal atoms after

energy is consistent with an assignment of $\mathrm{Au}(0)$ in the small cluster/ single atom form (McEleney et al., 2009; Sun et al., 2009; Anderson et al., 2013; Anderson et al., 2013).

Mercury (II) complexes, $\mathrm{HgI}_{2}$ or $\mathrm{Hg}\left(\mathrm{NO}_{3}\right)_{2}$ were found to have binding energies of $101.9 \mathrm{eV}$ and $101.6 \mathrm{eV}$. After incorporation into RHCC-NT the binding energy of mercury decreased to $100.8 \mathrm{eV}$ or $101.1 \mathrm{eV}$ starting from either $\mathrm{K}_{2} \mathrm{HgI}_{4}$ or $\mathrm{Hg}\left(\mathrm{NO}_{3}\right)_{2}$ respectively Fig. 2. In both cases the lowered binding energy is consistent with a reduction in metal oxidation state and these values are comparable with other values for $\mathrm{Hg}$ (0), especially for small clusters (Riskin et al., 2006; Bootharajau and Pradeep, 2010)

\subsection{X-ray crystallography analysis of the RHCC-NT in complex with $\mathrm{K}_{2} \mathrm{HgI}_{4}$}

To study the molecular uptake of mercury compounds we used ionic complexes such as mercury nitrate $\left[\mathrm{Hg}\left(\mathrm{NO}_{3}\right)_{2}\right]$ and dipotassium tetraiodomercurate $\left[\mathrm{K}_{2} \mathrm{HgI}_{4}\right]$, covalent mercury compounds, i.e. mercury bromide $\left[\mathrm{HgBr}_{2}\right]$ and mercury chloride $\left[\mathrm{HgCl}_{2}\right]$ or the alkylated mercury compounds like ethyl-mercury phosphate $\left[\mathrm{C}_{2} \mathrm{H}_{5} \mathrm{HgPO}_{4}\right]$ and methyl-mercury chloride $\left[\mathrm{CH}_{3} \mathrm{HgCl}_{2}\right]$. Remarkably, RHCC-NT could only uptake mercury complex ions, whereas neither binding and reduction of covalent mercury compounds nor alkylated mercury compounds was detectable. Thus there is a clear preference of the RHCC-NT for the bivalent $\mathrm{Hg}^{2+}$ cation.

Protein crystals of RHCC-NT were prepared as described previously and soaked for $24 \mathrm{~h}$ in a $0.7 \mathrm{mM} \mathrm{K}_{2} \mathrm{HgI}_{4}$ stock solution (Ozbek et al., 2005). After several minutes the crystals became red, indicating the presence of complex iodine anion species (Ozbek et al., 2005). The

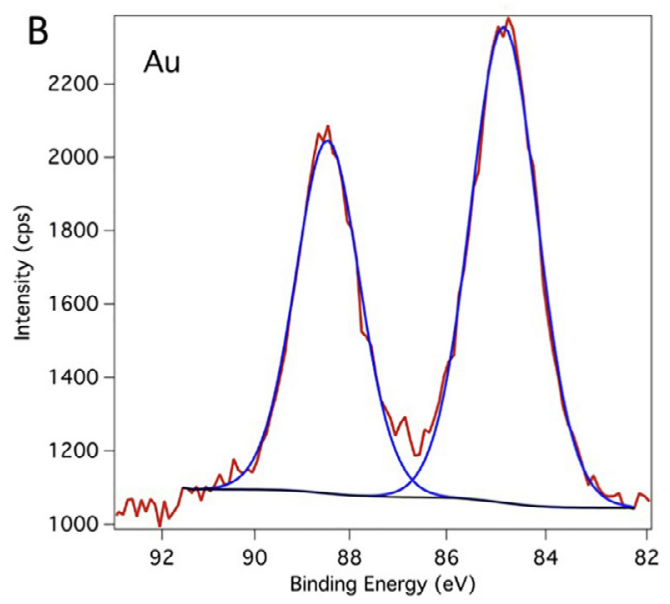

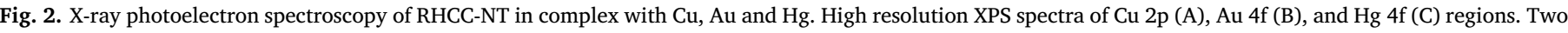
peaks were fitted in each spectra to represent the spin split states $(3 / 2,1 / 2$ of $2 p$ and $7 / 2,5 / 2$ of $4 f)$ of the orbitals. 
Table 2

Anomalous Signal of Protein-associated Mercury species.

\begin{tabular}{ll}
\hline Mercury Cluster & Anomalous Signal Strength \\
\hline $\mathrm{HgI}_{4}$ in Cavity 1 & No peak \\
$\mathrm{Hg}_{2}$ in Cavity 2 & $4.5 \sigma$ \\
$\mathrm{Hg}_{2}$ in Cavity 3 & $3.0 \sigma$ \\
$\mathrm{HgI}_{2}$ in Cavity 4 & $4.0 \sigma$ \\
$\mathrm{HgI}_{3}$ associated with Met39B & No Peak \\
$\mathrm{HgI}_{3}$ associated with Met39D & No Peak
\end{tabular}

* Anomalous signal strength is based on fourier difference peaks of data collected at $14.635 \mathrm{keV}$.

crystal data sets were collected at the absorption edge of mercury at $\lambda=0.8491 \AA(E=14600 \mathrm{eV})$ with a $f^{\prime} / f^{\prime \prime \prime}$ of $11.43 \mathrm{e}$. This data collection strategy allows for interpretation of anomalous signals at the absorption edge of mercury and to perform molecular finger print studies (see Table 2). When $\mathrm{K}_{2} \mathrm{HgI}_{4}$ was soaked into the RHCC-NT crystal, a number of different mercury species were present in the final structure, which was refined to $R_{\text {free }} / R_{\text {work }}$ of $0.2998 / 0.2817$ at $3.27 \AA$ resolution. As a result, anomalous fourier peaks at sigma levels $>4 \sigma$ were detectable inside the proteinaceous cavities Figs. 3 and 4). All the crystallographic data are summarized in Table 3.

Overall, the crystal structure of RHCC-NT retains the same homotetrameric parallel right handed coiled coil assembly as the native protein, with 4 large cavities of up to $8.6 \AA$ in diameter present in the hydrophobic interior. The overall r.m.s.d. in $\mathrm{C} \alpha$ positions is less than $0.5 \AA$ which indicates a very rigid tetrameric nanotube and a minor breathing effect upon mercury uptake (McFarlane et al., 2012; Ozbek et al., 2002). In contrast to previous structures of RHCC-NT, where the cavities have been filled with water (PDB 1FE6) and elemental sulphur (PDB 5JR5), all four cavities have large electron density peaks indicative of different mercury species (Stetefeld et al., 2000; McDougall et al., 2017). Interestingly, Met39is the only exterior side chain showing strong anomalous signals, which have been interpreted as $\mathrm{HgI}_{4}$ Fig. 3 and Supplement Fig. 2.

Clear density was observed in the $\mathrm{N}$-terminal cavity 1 for $\mathrm{KHgI}_{4}^{-}$, where two of the 4 RHCC-NT helices were forced to partially unwind to accommodate the bulky mercury species. Cavity 4 is occupied by the polar $\mathrm{HgI}_{2}$. All adjacent chains maintain helicity, but have shifted outward $\sim 1.3 \AA$ relative to the native structure, where a single water molecule resides in the cavity. Cavities 2 and 3 both contain strong mercury peaks corresponding to diatomic mercury particles in alternate conformations Fig. 4. These particles are bound above and below by aliphatic Leu and Ile sidechains and on the sides by the peptide backbone. All hydrogen donor and acceptors are fully satisfied in the $\alpha$ helical backbone; there are no moieties available to stabilize a charged species in these cavities. Together with the XPS data this suggests that these diatomic particles are in fact reduced metallic mercury.

\section{Discussion}

Coiled coils are known as oligomerization motifs which function as entropic clamps to increase the local number of protein domains (Burkhard et al., 2001; Lupas and Bassler, 2017; Lupas and Gruber, 2005). In this study we extend the view and describe the RHCC-NT as a unique oligomerization domain with the capability to reduce and uptake metal clusters inside its large sized hydrophobic cavities.

RHCC-NT lacks many of the common features associated with protein-metal interactions. The sequence is devoid of the common metal binding Cys and His residues, which often form metal thiol coordination complexes and have been described both in nature (Rees and Howard, 2003) and synthetic biology (Morozov and Ogawa, 2013). Instead, in RHCC-NT the metals occupy hydrophobic cavities at both termini (Cavity 1 and 4) and inside the tetrameric channel (Cavity 2 and 3).
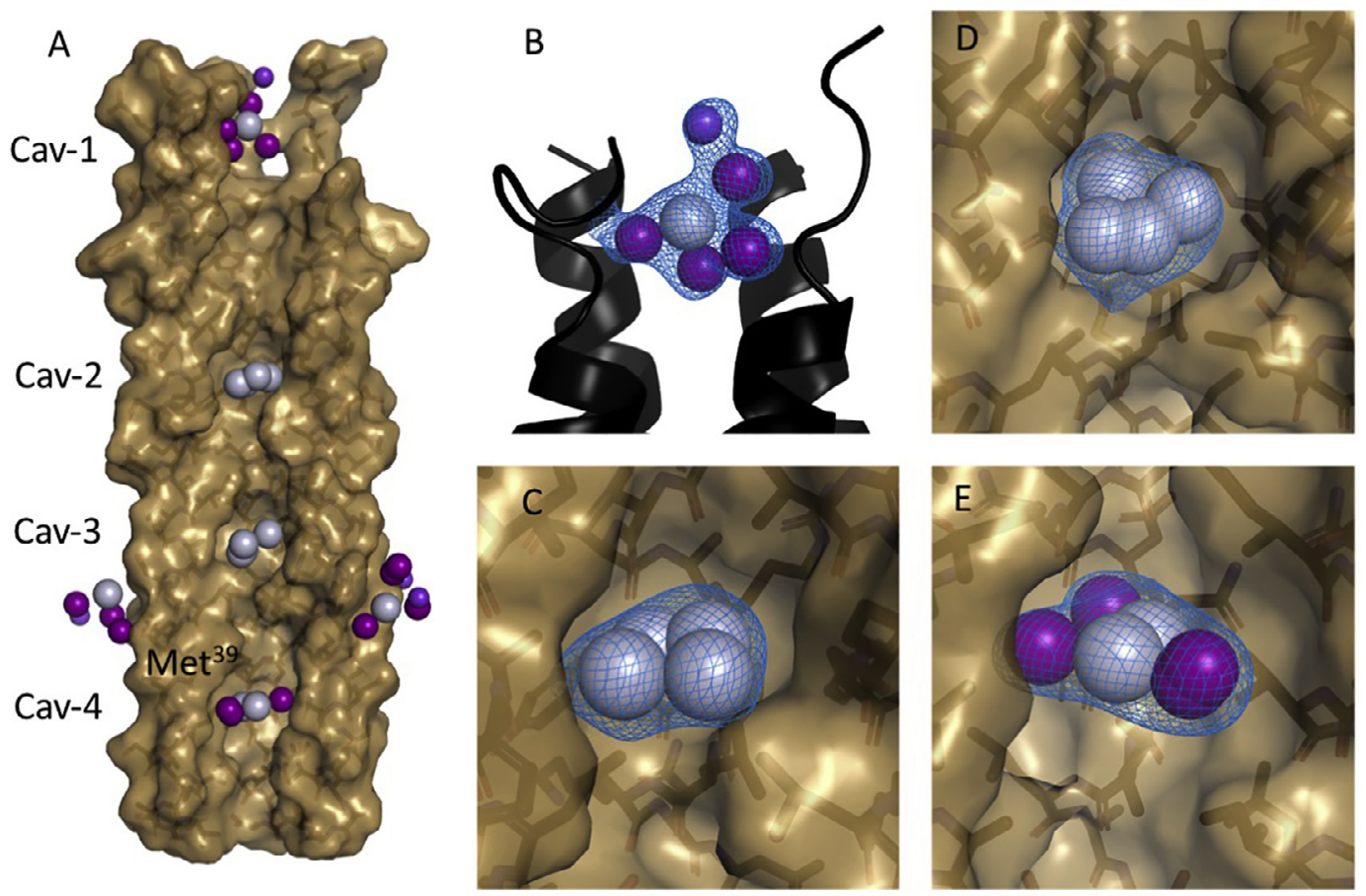

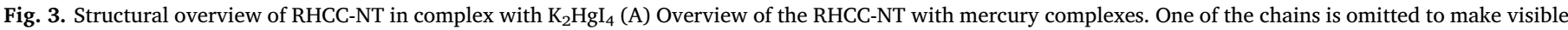

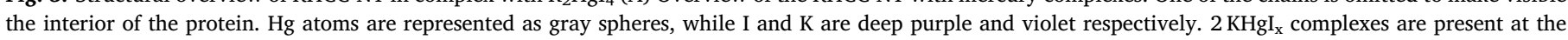

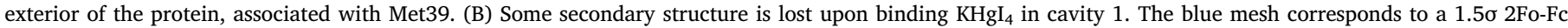

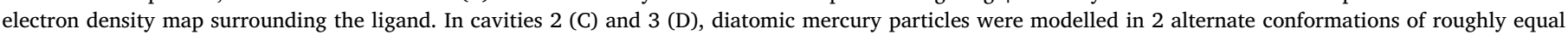

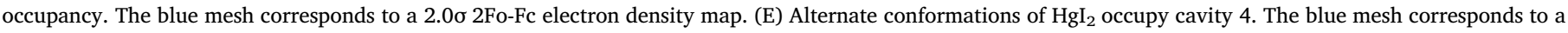
$2.0 \sigma 2$ Fo-Fc electron density map. 

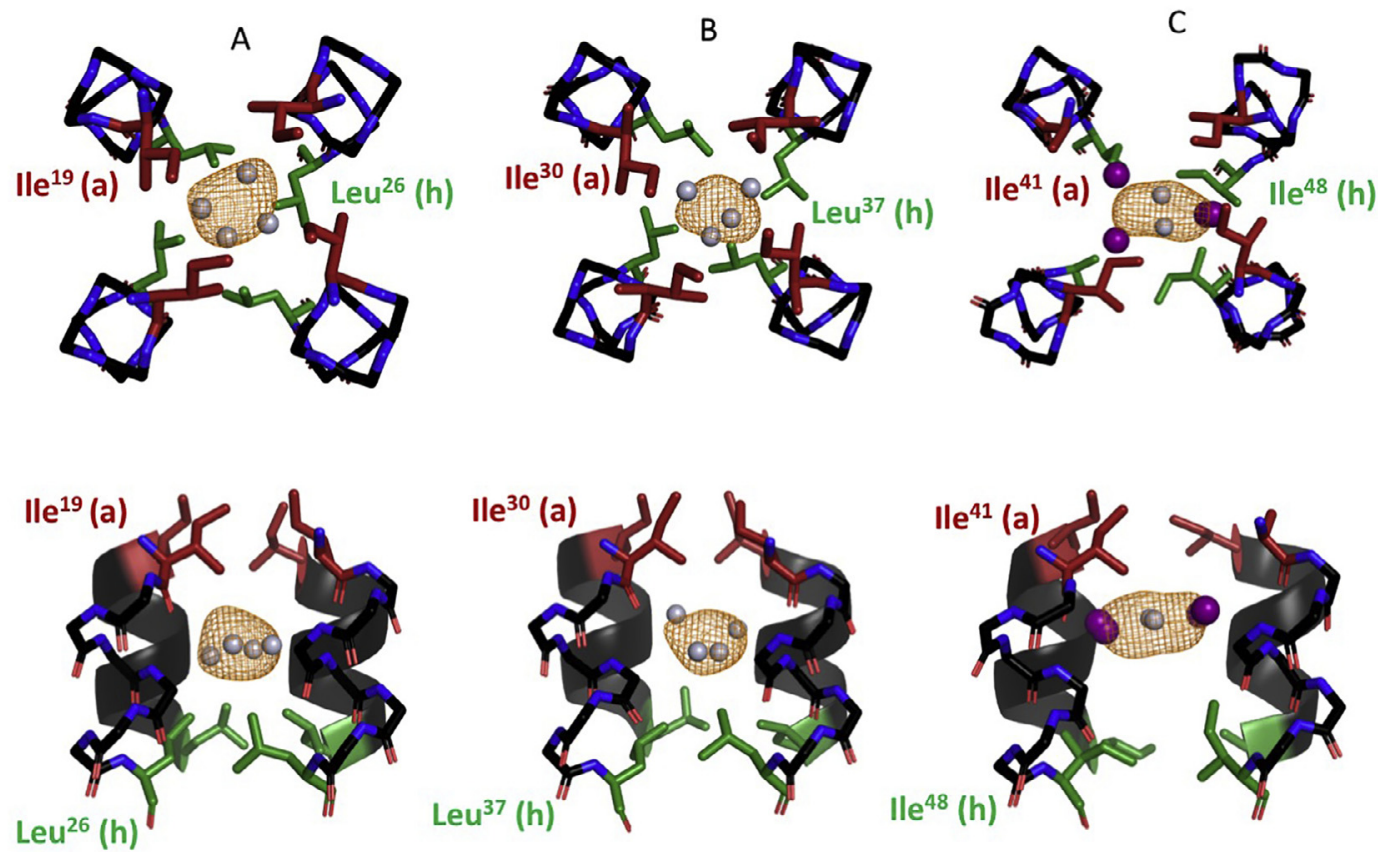

Fig. 4. Anomalous Electron density maps Top and side view of cavities 2 (A), 3 (B) and 4 (C) with 3.5 $\sigma$ anomalous difference electron density maps. a and $\mathbf{h}$ layers are highlighted in red and green respectively, while the other sidechains have been omitted for clarity. In cavities 2 and 3 , $\alpha$-helicity is maintained with the requisite peptide hydrogen bonding; there is no part of the protein available to stabilize a charged particle in these cavities. In cavity 4 the chains move slightly to accommodate the bulkier ligand. The electron density map was calculated using experimental $\Delta \mathrm{F}_{\text {ano }}$ and $\varphi_{\text {calc }}$ from apoRHCC.

Table 3

X-ray crystallography of the RHCC-NT in complex with $\mathrm{K}_{2} \mathrm{HgI}_{4}$.

\begin{tabular}{ll}
\hline Data Collection & RHCC-Hg \\
\hline$\lambda(\AA)$ & 0.8472 \\
Space Group & $\mathrm{P} 3121$ \\
Cell dimensions & \\
$a, b, c(\AA)$ & $108.82,108.82,70.39$ \\
$\alpha, \beta, \gamma\left({ }^{\circ}\right)$ & $90.00,90.00,120.00$ \\
No. unique reflections & 7550 \\
Resolution $(\AA)$ & $28.69-3.27(3.35-3.27)$ \\
${ }^{b} R_{\text {merge }}$ & $0.071(0.78)$ \\
$I / \sigma \mathrm{I}$ & $3.8(2.8)$ \\
Completeness $(\%)$ & $98.7(95.1)$ \\
Multiplicity & $3.7(3.4)$ \\
Anomalous Completeness (\%) & $99.1(95.6)$ \\
Anomalous Multiplicity & $2.8(2.4)$ \\
Refinement & \\
${ }^{\mathrm{c}} R_{\text {work }} / R_{\text {free }}$ & \\
No. atoms & $0.2737 / 0.2902$ \\
Protein & \\
Ligand/Ion & 1532 \\
$B$-factor $\left(\AA^{2}\right)$ & 55 \\
$\quad$ Protein/Ligands & 45.0 \\
R.m.s. deviations & $44.77 / 58.83$ \\
Bond lengths $(\AA)$ & \\
Bond angles $\left({ }^{\circ}\right)$ & 0.002 \\
Ramachandran (\%) Favoured/Allowed/Outliers & 0.51 \\
& $94.27 / 5.21 / 0.52$ \\
\hline
\end{tabular}

${ }^{\text {a }}$ Statistics of the highest resolution shell are shown in parenthesis.

${ }^{\mathrm{b}} R_{\text {merge }}=\sum_{h k l} \sum_{i=1}^{N}\left|I_{h k l, i}-\bar{I}_{h k l}\right| / \sum_{h k l} \sum_{i=1}^{N} I_{h k l, i}$

c $R_{f a c t o r}=\sum_{h k l}\left|F_{h k l}^{o b s}-F_{h k l}^{c a l c}\right| / \sum_{h k l} F_{h k l}^{o b s}$ The $\mathrm{R}_{\text {free }}$ was calculated by randomly omitting $10 \%$ of observed reflections from refinement.

A wealth of published articles show that several amino acid candidates present in RHCC-NT are known to be capable of reducing metals, including tyrosines (Selvakannan et al., 2004; Sahoo et al., 2017) and aspartates (Shao et al., 2004). The sulfur-containing thioether moieties of methionines form long, flexible sidechains, which are less polar and more hydrophobic than cysteines, however, reveal greater conformational flexibility. It has been shown in Cupper-binding proteins that the S-center of methionines can form strong covalent-like interactions with heavy metal ligands (Bozzi et al., 2016). Attempts to investigate the redox-mechanism in more detail failed because of either low expression rates and misfolded proteins (Met39 mutations) or unambiguous results (Tyr13 and Tyr23 blockages).

Remarkably, RHCC-NT is only capable of binding to bivalent cationic compounds such as mercury nitrate and iodide; no binding could be detected for the covalently bound or alkylated mercury compounds tested. Interestingly, mercury is not involved in the formation of hydrogen bonds between the CO-NH acceptor-donor system of the peptide backbone of the coiled-coil helices. It seems to be that the mercury species inside the cavity is the metallic $\mathrm{Hg}(0)$, which is known to be hydrophobic and volatile. This is further evidenced by the presence or absence of anomalous difference peaks for the individual mercury species, which correlates to the predicted oxidation states of the various mercury complexes.

This finding is very unusual and suggestive for a bimodal mechanism of interaction. Initially, the positive mercury cations associate with the charged exterior of RHCC-NT, where the metal is reduced. The breathing motions of the RHCC-NT allow the hydrophobic reduced metal atom into the aliphatic lined channel, where it moves away from the charged termini of the protein toward the neutral cavities 2 and 3 , replacing the polar water molecules. As a result, cavities 2 and 3 are filled with diatomic $\mathrm{Hg}$ particles showing alternate conformations in the crystal structure. Though structural data is only available for the RHCC-NT Hg complex, the reduced $\mathrm{Cu}$ and Au measured by XPS are likely in the interior of RHCC-NT. Reduced metal atoms are generally unstable in solution and tend to aggregate to first form nanoparticles and then, in the absence of a protective capping agent, large insoluble metal flakes of which none were observed. In addition, prior to XPS analysis both of these complexes were dialyzed against a Tris buffer solution where any loosely associated $\mathrm{Au}$ or $\mathrm{Cu}$ on the exterior of the protein would migrate from the sample. Therefore, the reduced metals observed by XPS must be encapsulated by RHCC-NT to avoid self-association and diffusion away from the sample. 
In this context it should be mentioned, that mercury is one of the most toxic metals on earth (Nies, 1999). Toxicity has been referred to inactivation of enzymes, displacement of metal cofactors and binding to lipids nucleotides and DNA. Resistance to mercury ions is seen to be ancient and is defined as narrow spectrum resistance Barkay, 2010 \#443\}. Interestingly, inorganic mercuric ions are chaperoned in the periplasm (using MerP) were they get reduced to non-toxic metallic mercury by reductases (MerA) to leave the bacterial cells by passive diffusion.

In Summary, the data presented show for the first time that the right-handed coiled coil, RHCC-NT, is involved in the reduction of bivalent cations and is able to incorporate metal $\mathrm{Hg}$-clusters inside a large-size hydrophobic cavity. Though there is some literature available on the properties of Au quantum dots containing only a small number of atoms, parallel data is lacking for other metals, including $\mathrm{Cu}$ and $\mathrm{Hg}$. RHCC-NT may provide a platform from which to study these unusual metal compounds (Zheng et al., 2004).

\section{Experimental procedures}

\subsection{Expression and purification of the RHCC-NT}

E. coli cells of strain BL21(DE3) were transformed with plasmid DNA containing an $\mathrm{N}$ terminal His6 -tag to aid in the purification of RHCCNT by affinity chromatography and a thrombin cleavage site that enables the cleavage of the His-tag residue after purification. Expression of the target protein is under the control of the T7 promoter which is IPTG inducible. The antibiotic resistance for the plasmid is ampicillin. The bacterial cell pellet from the $1.6 \mathrm{~L}$ expression culture was resuspended in $30 \mathrm{~mL}$ Binding buffer [20 mM Tris - HCl, pH 7.5, $5 \mathrm{mM}$ Imidazole, $500 \mathrm{mM} \mathrm{NaCl}, 8 \mathrm{M}$ Urea] and kept on ice. The cells were lysed by three passages through a French Pressure Cell (SLM Instruments, Urbana IL, U.S.A.). The purification of His-tagged RHCCNT was performed at room temperature by affinity chromatography on $\mathrm{Ni} 2+$-Sepharose (GE Healthcare) under denaturating conditions as described previously (Stetefeld et al., 2000). Removal of the His tag from the purified protein was achieved by using biotinylated thrombin, according to the manufacturers instruction (EMD Biosciences Inc.) This is possible as the PET15b vector contains a thrombin cleavage site between the His6-tag and the N-terminus of the expressed protein Fig. 3. The protein sample was incubated for $2,4,8$ and $16 \mathrm{~h}$ at room temperature (RT) to identify the optimal cleavage conditions. The cleavage reaction was stopped by a $10 \mathrm{~min}$ incubation of the reaction mix at $90^{\circ} \mathrm{C}$ in a water bath. After the heat inactivation step, the biotinylated thrombin was removed from the sample by passing the thrombin/ RHCC-NT mixture over a streptavidin agarose column according to the manufacturers protocol (EMB Biosciences Inc.). To ensure the complete removal of the thrombin from the sample, $32 \mu$ of slurry was required per unit of the thrombin protease used. The RHCC-NT with the His6-tag removed was then dialyzed into the desired buffer.

\subsection{Preparation of RHCC-NT Cu and Hg complexes}

The preparation of the $\mathrm{K}_{2} \mathrm{HgI}_{4}, \mathrm{CuCl}_{2}$, and $\mathrm{Hg}\left(\mathrm{NO}_{3}\right)_{2}$ RHCC-NT complexes began with the incubation of $5 \mathrm{mM}$ of the respective metal salts with $5 \mathrm{mg} / \mathrm{mL}$ RHCC-NT in $10 \mathrm{mM}$ Tris $\mathrm{pH}$ 8.0, I = $154 \mathrm{mM} \mathrm{(NaCl)}$ for 7 days. The $\mathrm{K}_{2} \mathrm{HgI}_{4}$ solution remained clear, while a cloudy precipitate appeared in the $\mathrm{CuCl}_{2}$, and $\mathrm{Hg}\left(\mathrm{NO}_{3}\right)_{2}$ solutions upon the addition of the metal. Solutions were then dialyzed in a 3000 Da MWCO membrane against $10 \mathrm{mM}$ Tris $\mathrm{pH} 8.0, \mathrm{I}=154 \mathrm{mM}(\mathrm{NaCl})$ overnight. All precipitate disappeared. Solutions were then lyophilized for XPS measurement.

\subsection{Preparation of RHCC-NT Au complex}

RHCC-Au was formed by the addition of $1 \mu \mathrm{mol}$ of $\mathrm{KAuCl}_{4}$ to $3 \mathrm{~mL}$ of
$1 \mathrm{mg} / \mathrm{mL}$ RHCC-NT in $10 \mathrm{mM}$ bicine, $154 \mathrm{mM} \mathrm{NaCl}$. The $\mathrm{pH}$ was continually adjusted to 8.5 with $1 \mathrm{M} \mathrm{NaOH}$ until it became stable. The $\mathrm{pH}$ stability was accompanied by the appearance of a dark purple colouration, indicative of the formation of RHCC-NT capped Au-nanoparticles $>5 \mathrm{~nm}$ in diameter. As we were interested in studying metal complexes encapsulated in the RHCC-NT cavities, these larger species were separated by FPLC with a Superdex 75 column and the peak fraction corresponding to the RHCC-NT tetramer was isolated and lyophilized for XPS analysis. Absorbance at $>500 \mathrm{~nm}$ corresponding to the SPR band of larger Au-nanoparticles was absent in these peak fractions.

\subsection{XPS}

Samples of RHCC-NT loaded with different metal complexes were lyophilized and the powder pressed into double sided conductive copper tape for analysis by XPS. A Kratos Axis Ultra DLD X-ray photoelectron spectrometer was used with a base pressure of $10^{-9}$ torr. A monochromatic $\mathrm{Al} \mathrm{K \alpha}$ anode $(1486.6 \mathrm{eV})$ with $15 \mathrm{~mA}$ emission current and $15 \mathrm{kV}$ anode voltage was used to excite the photoelectrons. Spectra were collected in a fixed analyzer transmission mode with a pass energy of $160 \mathrm{eV}$ was used for survey scans and $20 \mathrm{eV}$ for high resolution elemental scans. A co-axial charge neutralizer was used to minimize the effects of sample charging and all spectra were charge referenced to the aliphatic C $1 \mathrm{~s}$ peak at $285 \mathrm{eV}$. Peak fitting of the high resolution spectra was performed with CasaXPS using a Shirley background. The reported binding energies are an average of two to three measurements.

\subsection{Protein X-ray crystallography}

Protein samples of RHCC-NT were crystallized by hanging drop vapour diffusion in $2 \mathrm{M}$ ammonium sulfate, $200 \mathrm{mM}$ Tris $\mathrm{pH} 7.9$ as described previously (Stetefeld et al., 2000). Dipotassium tetraiodomercurate was soaked in the crystal at a concentration of $0.7 \mathrm{mM}$ for 4 days prior to data collection at $100 \mathrm{~K}$ at the BW7B beamline at DESY with a $0.8472 \AA$ wavelength. Crystals were cryoprotected in $15 \%$ glycerol. The crystals belong to the space group P $3_{1} 21$ and contain one molecule RHCC-NT per asymmetric unit. Diffraction images were processed using the program suite MOSFLM (Leslie, 1994) and the CCP4 package (CCP4. Collaborative Computing Project No. 4, 1994). The model was built and refined without NCS-restraints using COOT (Emsley et al., 2010) and the Phenix Software package (Adams et al., 2011). Table 3 summarizes Data collection and refinement parameters. The structure factor amplitudes and the protein coordinates were deposited at RCSB under the pdb-code: 6BRI.

\section{Acknowledgements}

The presented work was funded by the Natural Science and Engineering Council of Canada (RGPIN 342077-2012, RGPIN-0049542017 and STGP 479210-2015). JS is a Canada Research Chair in Structural Biology and Biophysics. We thank the Canadian Light Source (CLS) and the Deutsche Elektron Synchrotron (DESY) for beamtime and technical support. The authors would like to thank the Manitoba Institute for Materials for support of the X-ray photoelectron experiments.

\section{Conflict of interest}

There is no conflict of interest to declare.

\section{Appendix A. Supplementary data}

Supplementary data associated with this article can be found, in the online version, at http://dx.doi.org/10.1016/j.jsb.2018.05.013. 


\section{References}

Adams, P.D., Afonine, P.V., Bunkoczi, G., Chen, V.B., Echols, N., Headd, J.J., et al., 2011. The Phenix software for automated determination of macromolecular structures. Methods 55, 94-106.

Anderson, D.P., Alvino, J.F., Gentleman, A., Qahtani, H.A., Thomsen, L., Polson, M.I., et al., 2013. Chemically-synthesised, atomically-precise gold clusters deposited and activated on titania. Phys. Chem. Chem. Phys. 15, 3917-3929.

Anderson, D.P., Adnan, R.H., Alvino, J.F., Shipper, O., Donoeva, B., Ruzicka, J.Y., et al., 2013. Chemically synthesised atomically precise gold clusters deposited and activated on titania. Part II. Phys. Chem. Chem. Phys. 15, 14806-14813.

Berwick, M.R., Lewis, D.J., Jones, A.W., Parslow, R.A., Dafforn, T.R., Cooper, H.J., et al., 2014. De novo design of Ln(III) coiled coils for imaging applications. J. Am. Chem. Soc. 136, 1166-1169.

Bootharajau, M., Pradeep, T., 2010. Uptake of toxic metal ions from water by naked and monolayer protected silver nanoparticles: an X-ray photoelectron spectroscopic investigation. J. Phys. Chem. C 114, 8328-8336.

Bozzi, A.T., Bane, L.B., Weihofen, W.A., McCabe, A.L., Singharoy, A., Chipot, C.J., et al., 2016. Conserved methionine dictates substrate preference in Nramp-family divalent metal transporters. Proc. Natl. Acad. Sci. U.S.A. 113, 10310-10315.

Burkhard, P., Stetefeld, J., Strelkov, S.V., 2001. Coiled coils: a highly versatile protein folding motif. Trends Cell Biol. 11, 82-88.

CCP4. Collaborative Computing Project No. 4, 1994. The CCP4 suite: programs for protein crystallography. Acta Cryst. 1994 (D50), 760-763.

Dalili, N., He, A., Qi, L., Ivey, D.G., 2010. A Cryo-XPS study of triammonium citrateKAuCl4-Na2SO3 electroplating solutions for Pb-Free solder packaging. J. Electron. Mater. 39, 1554-1561.

Emsley, P., Lohkamp, B., Scott, W.G., Cowtan, K., 2010. Features and development of Coot. Acta Crystallogr. D Biol. Crystallogr. 66, 486-501.

Eriksson, M., Hassan, S., Larsson, R., Linder, S., Ramqvist, T., Lovborg, H., et al., 2009 Utilization of a right-handed coiled-coil protein from archaebacterium Staphylothermus marinus as a carrier for cisplatin. Anticancer Res. 29, 11-18.

Fiala, G., Stetter, K.O., Jannasch, H.W., Langworthy, T.A., Madon, J., 1986. Staphylothermus marinus sp. nov. represents a noverl genus of extremely thermophillic submarine heterotrophic archeabacteria grwoing up to 98C. Syst. Appl. Microbiol. 8, 106-113.

Gellman, S.H., 1991. On the role of methionine residues in the sequence-independent recognition of nonpolar protein surfaces. Biochemistry. 30, 6633-6636.

Hao, X., Ma, K., 2003. Minimal sulfur requirement for growth and sulfur-dependent metabolism of the hyperthermophilic archaeon Staphylothermus marinus. Archaea 1, 191-197.

Hartmann, M.D., Ridderbusch, O., Zeth, K., Albrecht, R., Testa, O., Woolfson, D.N., et al., 2009. A coiled-coil motif that sequesters ions to the hydrophobic core. Proc. Natl. Acad. Sci. U.S.A. 106, 16950-16955.

Leslie, A.G.W., 1994. MOSFLM Users Guide. MRC-LMB, Cambridge.

Lupas, A.N., Bassler, J., 2017. Coiled coils - a model system for the 21st Century. Trends Biochem. Sci. 42, 130-140.

Lupas, A.N., Gruber, M., 2005. The structure of alpha-helical coiled coils. Adv. Protein Chem. 70, 37-78.

Matzapetakis, M., Farrer, B.T., Weng, T.C., Hemmingsen, L., Penner-Hahn, J.E., Pecoraro, V.L., 2002. Comparison of the binding of cadmium(II), mercury(II), and arsenic(III) to the de novo designed peptides TRI L12C and TRI L16C. J. Am. Chem. Soc. 124, 8042-8054.

Mayr, J., Lupas, A., Kellermann, J., Eckerskorn, C., Baumeister, W., Peters, J., 1996. A hyperthermostable protease of the subtilisin family bound to the surface layer of the archaeon Staphylothermus marinus. Curr. Biol. CB. 6, 739-749.

McDougall, M., Francisco, O., Viddal, C., Roshko, R., Meier, M., Stetefeld, J., 2017. Archaea S-layer nanotube from a "black smoker" in complex with cyclo-octasulfur S8 rings. Proteins.

McEleney, K., Crudden, C.M., Horton, J.H., 2009. X-ray photoelectron spectroscopy and the auger parameter as tools for characterization of silica-supported Pd catalysts for the suzuki-miyaura reaction. J. Phys. Chem. C 113, 1901-1907.

McFarlane, A.A., Orriss, G.L., Stetefeld, J., 2009. The use of coiled-coil proteins in drug delivery systems. Eur. J. Pharmacol. 625, 101-107.

McFarlane, A., Orriss, G., Okun, N., Meier, M., Klonisch, T., Khajehpour, M., et al., 2012.
The pentameric channel of COMPcc in complex with different fatty acids. PLoS ONE 7, e48130.

Morozov, V.A., Ogawa, M.Y., 2013. Controlled formation of emissive silver nanoclusters using rationally designed metal-binding proteins. Inorgan. Chem. 52, 9166-9168.

Nies, D.H., 1999. Microbial heavy-metal resistance. Appl. Microbiol. Biotechnol. 51, 730-750.

Odoh, S.O., Walker, S.M., Meier, M., Stetefeld, J., Schreckenbach, G., 2011. QM and QM/ MM studies of uranyl fluorides in the gas and aqueous phases and in the hydrophobic cavities of tetrabrachion. Inorg. Chem. 50, 3141-3152.

Orriss, G.L., Patel, T.R., Sorensen, J., Stetefeld, J., 2010. Absence of a catalytic water confers resistance to the neurotoxin gabaculine. FASEB J. 24, 404-414.

Ozbek, S., Engel, J., Stetefeld, J., 2002. Storage function of cartilage oligomeric matrix protein: the crystal structure of the coiled-coil domain in complex with vitamin $D(3)$. ЕМBO J. 21, 5960-5968.

Ozbek, S., Muller, J.F., Figgemeier, E., Stetefeld, J., 2005. Favourable mediation of crystal contacts by cocoamidopropylbetaine (CAPB). Acta Crystallogr. D Biol. Crystallogr. 61, 477-480.

Peacock, A.F., 2013. Incorporating metals into de novo proteins. Curr. Opin. Chem. Biol. 17, 934-939.

Peacock, A.F., 2016. Recent advances in designed coiled coils and helical bundles with inorganic prosthetic groups-from structural to functional applications. Curr. Opin. Chem. Biol. 31, 160-165.

Peters, J., Nitsch, M., Kuhlmorgen, B., Golbik, R., Lupas, A., Kellermann, J., et al., 1995 Tetrabrachion: a filamentous archaebacterial surface protein assembly of unusual structure and extreme stability. J. Mol. Biol. 245, 385-401.

Peters, J., Baumeister, W., Lupas, A., 1996. Hyperthermostable surface layer protein tetrabrachion from the archaebacterium Staphylothermus marinus: evidence for the presence of a right-handed coiled coil derived from the primary structure. J. Mol. Biol. 257, 1031-1041.

Rees, D.C., Howard, J.B., 2003. The interface between the biological and inorganic worlds: iron-sulfur metalloclusters. Science 300, 929-931.

Riskin, M., Basnar, B., Katz, E., Willner, I., 2006. Cyclic control of the surface properties of a monolayer-functionalized electrode by the electrochemical generation of $\mathrm{Hg}$ nanoclusters. Chem. Eur. J. 12, 8549.

Sahoo, J.K., Roy, S., Javid, N., Duncan, K., Aitken, L., Ulijn, R.V., 2017. Pathway-dependent gold nanoparticle formation by biocatalytic self-assembly. Nanoscale 9 , 12330-12334.

Seah, M.P., Gilmore, I.S., Spencer, S.J., 1998. XPS: binding energy calibration of electron spectrometers 4- assessment of effects for different x-ray sources, analyser resolutions, angles of emission and overall uncertainties. Surf. Interface Anal. 26, 642.

Selvakannan, P.R., Swami, A., Srisathiyanarayanan, D., Shirude, P.S., Pasricha, R. Mandale, A.B., et al., 2004. Synthesis of aqueous Au core-Ag shell nanoparticles using tyrosine as a pH-dependent reducing agent and assembling phase-transferred silver nanoparticles at the air-water interface. Langmuir 20, 7825-7836.

Shao, Y., Jin, Y., Dong, S., 2004. Synthesis of gold nanoplates by aspartate reduction of gold chloride. Chem. Commun. (Camb) 1104-5.

Stetefeld, J., Jenny, M., Schulthess, T., Landwehr, R., Engel, J., Kammerer, R.A., 2000. Crystal structure of a naturally occurring parallel right-handed coiled coil tetramer. Nat. Struct. Biol. 7, 772-776.

Sun, Y., Wang, Y., Pan, J., Wang, L., Sun, C., 2009. Elucidating the 4f binding energy of an isolated Pt atom and its bulk shift from the measured surface- and size-induced Pt $4 \mathrm{f}$ core level shift. J. Phys. Chem. C 113, 14696-14701.

Thanasupawat, T., Bergen, H., Hombach-Klonisch, S., Krcek, J., Ghavami, S., Del Bigio, M.R., et al., 2015. Platinum (IV) coiled coil nanotubes selectively kill human glioblastoma cells. Nanomed. Nanotechnol. Biol. Med.

Yamashita, M.M., Wesson, L., Eisenman, G., Eisenberg, D., 1990. Where metal ions bind in proteins. Proc. Natl. Acad. Sci. U.S.A. 87, 5648-5652.

Yin, H., Hummer, G., Rasaiah, J.C., 2007. Metastable water clusters in the nonpolar cavities of the thermostable protein tetrabrachion. J. Am. Chem. Soc. 129, 7369-7377.

Zastrow, M.L., Peacock, A.F., Stuckey, J.A., Pecoraro, V.L., 2011. Hydrolytic catalysis and structural stabilization in a designed metalloprotein. Nat. Chem. 4, 118-123.

Zheng, J., Zhang, C., Dickson, R.M., 2004. Highly fluorescent, water-soluble, size-tunable gold quantum dots. Phys. Rev. Lett. 93, 077402. 